\title{
A RELAÇÃO ENTRE HISTÓRIA, FICÇÃO E FUNÇÃO POÉTICA NA OBRA PERFUME DE RESEDÁ, DE PAULO JOSÉ CUNHA
}

\author{
David Araújo de Carvalho \\ Pós-graduando em Gramática, Produção e Revisão Textual pela Faculdade Evangélica do \\ Meio Norte (FAEME) \\ davidcubas777@hotmail.com \\ Francisco Armando de Sousa Oliveira \\ Mestre em Letras pela Universidade Federal do Piauí, Professor da Faculdade \\ Evangélica do Meio Norte (FAEME) \\ armandooliveira@live.com
}

\section{RESUMO}

Neste trabalho, pretendemos realizar uma análise da distinção entre história e ficção na obra Perfume de Resedá (2009), de Paulo José Cunha. Distinguir história e ficção é uma atividade posta em conflito na produção literária. Visto que a obra literária não retrata o real, o fato, por meio de uma visão mais positivista de história acabada, mas uma possibilidade, uma representação dos sujeitos, espaços e tempos. Realizaremos um breve estudo acerca da função da poesia e do poeta na sociedade moderna, sendo este o segundo objetivo do artigo. Para realizar este trabalho, abordaremos autores como Freitas (1986), Chaves (1991), Moisés (2007), dentre outros.

Palavras-chave: História; Ficção; Função Poética.

\begin{abstract}
In this paper, we intend to establish an analysis of the distinction between history and fiction the work Perfume de Resedá (2009), by Paulo José Cunha. Distinguishing history and fiction is an activity that engenders conflict in literary productions. Since a literary work does not portray that which is real, a fact through a positivist vision of finished history, but rather a possibility, a representation of subjects, spaces and times. We will also develop a brief study of the function of poetry and of the poet in modern society. In order to so, we will turn to authors such as Freitas (1986), Chaves (1991), Moisés (2007) and others.
\end{abstract}

Keywords: History. Fiction. Poetic function. 


\section{CONSIDERAÇÕES INICIAIS}

O texto literário traz em si marcas da história, dos costumes, do social, marcas da língua de uma nação. Um retrato memorável de um narrador, de um eu lírico. A poesia percorreu grandes momentos da história, desde as líricas orais do canto acompanhado às liras, instrumento musical utilizado pelos gregos, aos romances românticos de José de Alencar, à poesia social de Carlos Drummond de Andrade, à revolução escrita de Salgado Maranhão. Porém, é certo dizer que a produção literária, a ficção: é história? É o real? É o fato ocorrido? Há como estabelecer o que é história e o que é ficção? A ficção pode andar dissociada da história?

Não há como negar que a produção literária ultrapassa a realidade histórica como fato vivido, mas não se tem como negar a participação da história para a produção da ficção, nem se pode afirmar categoricamente que uma precisa da outra para existir. Há vários setores que influenciam e que propiciam a produção da ficção. Realidades linguísticas, sociais, geográficas, históricas, políticas, econômicas etc., que interferem ou norteiam a percepção do escritor, do narrador com juízos de valor e costumes de épocas. No entanto, o objetivo principal deste trabalho será analisar a contribuição da história para a criação da ficção na literatura brasileira, o que e como o autor utiliza da história para dar forma ao seu trabalho. Em seguida, abordaremos as discussões estabelecidas por teóricos como Chaves (1991), Freitas (1986), Ribeiro (2009), dentre outros.

Utilizaremos como corpus a obra Perfume de Resedá (2009), de Paulo José Cunha. A obra é uma construção poética em que traz para as discussões lembranças do autor, "fatos", "causos" ocorridos na sua infância em que, em uma tentativa de resgate, o autor mergulha no seu in/consciente como uma busca para reviver o passado. Como diz o autor 
sobre a própria obra, "na infância, realidade e ficção são precisamente a mesma coisa" (CUNHA, 2009, p. 10).

Não há como deixar de lado a contribuição da história para a construção da ficção, especificamente da ficção poética, pois não se trata do corpus analisado, nem da função da poesia no meio que a cerca. É por meio de esse olhar, em se discutir a função da poesia, de sua representação no meio, que será abordado Moisés (2007). Diante disso, convém distinguir onde começa e onde termina a história na ficção e qual o papel que a poesia assume diante do leitor e da sociedade.

\section{História e ficção na literatura brasileira/piauiense}

Em toda a história do percurso da literatura como ficção, a História ${ }^{1}$ esteve presente e ausente na criação literária. Porém, sua participação na construção e na constituição da ficção é quase inexistente. Não se pode se conceber a literatura como um produto da história, visto que a história, propriamente dita, busca compreender os fatos reais na vida e no mundo. De tal modo, a ficção não busca reconstruir o fato, mas recriar uma possibilidade de leitura, de construção, pois, ao mesmo tempo em que a ficção se distancia do relato histórico, a produção literária permanece apreendida por suas condições de produção em que estão envolvidos aspectos geográficos, sociais, ideológicos, políticos, existenciais, históricos, etc.

Em um estudo de Chaves (1991), em que o autor aborda a presença da "História e da Ficção na literatura brasileira", em especial a de José de Alencar, o autor revela marcas presentes em analisar a ficção histórica do escritor, na qual se fazem presentes elementos ufanistas de exaltação da natureza, da pátria, do povo, da gente residente no território nacional, da constituição do brasileiro, dos conflitos sociais, da terra virgem. Não há 
método nem meio de excluir a História na ficção do autor de acordo com concepção que o autor nos oferece como "uma visão de mundo". Ainda em seu trabalho sobre História e Ficção, o autor nos esclarece como conceber um romance histórico:

... não é histórica aquela literatura que compete com a crônica pura e simples dos fatos ou inclui em sua matéria eventos e figuras decalcadas diretamente sobre a existência real. Entretanto poderá sê-lo (e com maior força de convicção) aquela que, embora totalmente fictícia, assume como preocupação central a História e a expressão de uma visão de mundo. (CHAVES, 1991, p. 22)

Diante disso, a obra literária não se envolve diretamente com os relatos reais da história, ela ultrapassa as esferas de sujeito-espaço-tempo. A ficção transcende a história, ela não tem um objetivo comum puro e simples, ela pode representar e se auto representar. De acordo com Freitas:

Se considerarmos as relações da ficção com realidade exterior, podemos estabelecer uma distinção fundamental entre dois tipos de obra literária: a representativa - aquela que conta uma histórica cujo referencial pode, em maior ou menor grau, ser encontrado na realidade exterior, considerada representação ou imagem do mundo real - e a obra auto-representativa aquela que só representa a si mesma, que se coloca em evidencia enquanto linguagem e elemento autônomo, independente do mundo que a cerca. (1986, p. 42)

Como bem descreve a autora, a produção literária possui seu envolvimento, seu entrelaçar com a história e sua autossuficiência. Questões são levantadas acerca dos romances, da ficção em geral, o que tem por objetivo um romance, uma ficção? Representar o real? De acordo com a autora, não é a descrição do real que busca a atividade literária, mas uma possibilidade de representação, o que se dará o nome de verossimilhança. O meio faz presença no processo da criação literária, porém só o faz porque seu criador está situado histórica e socialmente nas condições de produção de 
seu discurso. Por fim, é a realidade estética, a transfiguração do real, a ressignificação do meio, a plurissignificação que dará corpo ao texto literário. A realidade objetiva e a dicionarização das palavras só trazem aquilo que já está pronto e acabado, a matéria objetiva apresentada ao escritor. O escritor busca recriar essa realidade objetiva, ele infringe a história. De tal forma, o autor determina escolhas, estas que fazem parte da subjetividade de um eu criador, cheio de particularidade, momentos metamorfoseados pelas fazes de sua vida.

Diante das escolhas, fazem-se presentes razões fundamentais para se produzir a obra de ficção e sua relação com a história, com a demarcação do tempo, em que Freitas (1986) as distingue em três principais, seriam elas: estéticos, ideológicos, e pragmáticos. O estético determinaria a obra em dado gênero, no caso a ser analisado o poema. O ideológico, representado pela visão de mundo que o autor carrega em si, suas ideias e doutrinas da qual faz. O pragmático diz respeito às suas consequências, as ações tidas pelo leitor ao se deparar com o tema, com desenvolvimento da leitura em fazer o leitor ser captado ou de o leitor rejeitar a obra.

Outro fator importante está em destacar as infrações que a ficção realiza ao lidar com a história. O escritor sente-se no livre direito e poder de negar os dados fornecidos pela história. Não é de sua responsabilidade descrever e registrar os fatos de acordo com os dados. O escritor pode burlar com o tempo, com o espaço e com os personagens. Questões diante essa infração da ficção na história são levantadas, onde que por meio da infração, da transgressão, a História serve de elemento para a literatura. Contudo, é discutível revelar que a História, assim como a literatura, também representa variações de informações. De acordo com Freitas (1986): 
Se alguns elementos levam a crer que a ficção só existe em função da História, a análise em profundidade permite captar um movimento inverso: ao constatar que as informações históricas oscilam sem cessar entre o real e o fictício por razões estéticas, ideológicas ou pragmáticas, percebe-se que na verdade a História é adaptada às intenções especificamente literárias do escritor; ela perde então seu estatuto de referencial autônomo, e se torna elemento constitutivo do universo interno do romance e ficção. (FREITAS, 1986, p. 36)

Em um artigo intitulado "Aspectos dos romances históricos tradicional e pósmoderno" (2009), Ribeiro traz para o texto discussões sobre diversos teóricos que se propuseram a estudar o romance histórico. Diante disso, autora esboça algumas categorias em que possibilitam a construção do romance histórico como sendo aquele em que a "ação do romance se desenvolveria num passado anterior ao presente do escritor" (RIBEIRO, 2009, p. 74). É fácil identificar que o escritor se utiliza de fatos ocorridos em sua época os transcrevendo e os transfigurando à sua maneira. Na obra de Cunha, pode-se identificar as transformações modernas ocorridas no espaço em que o eu-lírico se insere. O confronto entre a tradição e a modernidade pela urbanização do espaço, pelas transformações ocorridas nos sujeitos presentes na obra. A presença de costumes, ritos religiosos e práticas dos sujeitos marcam aquilo em que a história se vale para reafirmar sua participação na obra de arte. Desse modo, não se pode negar que há envolvimento da história na ficção. Porém, sua participação está à mercê da atividade de criação do escritor.

É por essa manipulação, essa estratégia discursiva utilizada pelo escritor que a obra literária ganha seu valor de produto autêntico, autossuficiente. Ferreira, analisando a Poética de Aristóteles, afirma que:

A ficção surge, portanto, no pensamento de Aristóteles, como o território da verossimilhança, ou seja, daquilo que sem ser real é possível de se crer que tenha ou possa ter acontecido. O verossímil não é mais, portanto, que uma analogia do verdadeiro, e por isso pode-se dizer que a ficção é a capacidade de 
um fazer-crer, mercê do qual o artístico é tomado como um testemunho autêntico sobre a realidade e vida. Ou seja, a arte da ficção manifesta-se como arte da ilusão. (FERREIRA, 2010, p. 67)

É por meio dessa verossimilhança que Perfume de Resedá (2009) se enquadra nessa arte da ilusão, na qual o eu lírico mergulha no mais profundo de sua memória para recriar, para representar os sentimentos de mocidade, as travessuras de sua meninice, para falar da Chapada do Corisco, para falar das mazelas da seca deixada para os migrantes cearenses afligidos pela terra, entregues à sezão. De acordo com Silva "A arte literária é produto das bases históricas do meio em que surge, trazendo em si as características sociais, psíquicas, econômicos e culturais de certa comunidade. Expões suas mazelas, seus dramas, seus costumes, suas chagas e suas inquietações" (2013, p. 21).

A este gênero, que tanto transborda a visão do leitor, que ultrapassa as linhas do tempo, que fez Platão excluir de sua República o poeta, dá-se o nome de poesia. A poesia, que incomoda a ordem do sistema, que mexe com as emoções das leitoras e leitores, que fez José Cunha recriar seu mundo de criança nas folhas brancas de um livro, que traz para a modernidade e para a pós-modernidade uma preocupação sobre o esquecimento da tradição, dos costumes, dos valores, das crendices regionais de sua terra. Esses e outros apontamentos que, tanto fizeram o leitor pensar e refletir por meios das condições de recepção, quanto o escritor criar, por meio das condições de produção, sua obra, sua arte, fazem surgir um questionamento sobre a função da poesia nos dias atuais. Por meio disso, um questionamento é indispensável a esse trabalho: o que busca a poesia no século XXI? É sobre esse questionamento que Moisés disserta em seu trabalho intitulado "Poesia e Utopia: sobre as funções sociais da poesia e do poeta" (2007). 
Para Moisés (2007), em sua luta para compreender e refutar a proposição de Platão sobre uma sociedade sem poeta, afirma que não há meio de deserdar o poeta do convívio social, nem de definir uma função e classificar a poesia, pois para ele, a poesia ganha diferentes contornos dependendo de quem a vê. O termo passa a ganhar significados diferentes se for dirigido a um professor, a um filósofo, a um "homem comum", a um cirurgião. Para o autor, a poesia tem o papel de "ensinar a ver diferente". O autor declara:

\begin{abstract}
Se quisermos saber par que serve a poesia, num país como o Brasil, no século XXI etc., devemos perguntá-lo a alguém de fora, a um não especialista, que detenha o conhecimento suficiente da sociedade real à qual a pergunta se endereça, propiciando-nos desse modo a comprovação da resposta possível. Será essa a única maneira de superar o impasse representado pela inespecificidade dos âmbitos abrangidos pela reposta especializada, conforme propõe o parágrafo anterior. Como estamos interessados no que a poesia representa ou significa para nós, homens comuns, e não a miragem do que viria a ser a poesia "em si", não importa o não-especialista, a quem nos dirigimos, eventualmente não tenha, no que se refere à poesia, a familiaridade ou qualificação que exigimos do cirurgião, do administrador, do técnico em computação ou do perito em edifícios que desabam, cada qual em sua especialidade. (MOISÉS, 2007, p. 117)
\end{abstract}

Dessa forma, fica o questionamento sobre a proposição do pesquisador, como não atribuir valor ao significado dado pelo especialista em linguística e em teoria literária acerca do que vem a ser poesia e a sua função social? Como não compreender a historicidade da poesia e do poeta sem recorrer aos estudiosos da área? Pois é através deles que se obterão informações e conhecimento sobre os trabalhos de Camões, de Fernando Pessoa, de Homero, das obras dos escritores/poetas clássicos e modernos. Mas, como foi bem colocado pelo autor, não se podem restringir os significados aos especialistas, pois a obra, a arte poética, busca atingir a um público, às vezes, especificado, às vezes, sem delineação de público leitor. 
Por meio da discussão tomada sobre história, ficção e função da poesia, realizaremos a aplicação desse estudo teórico na obra poética de Paulo José Cunha.

\section{História, ficção e função poética na obra Perfume de Resedá}

A obra se inicia com a apresentação da origem, da gênese de sua criação. $O$ eulírico a apresenta como sendo criação do mais fundo de sua lembrança, do oco do mundo. A apresentação com a expressão lexical "oco do mundo" nos traz a ideia de início, de começo, de onde tudo surgiu. A marca do tempo, em que o eu-lírico utiliza para descrever sua obra, faz surgir eventualmente a construção do espaço onde surge a Chapada do Corisco, antigo nome dado ao local em que foi erguida Teresina, capital do estado do Piauí.

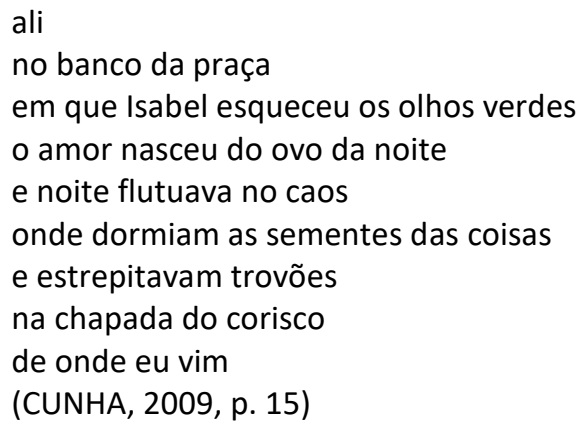

Pode-se perceber a luta entre o passado e o presente moderno. 0 passado do fundo das lembranças do eu-lírico, o passado histórico do lugar de onde vieram essas lembranças, de onde surgiu o eu-lírico. A Chapada do Corisco, o espaço-temporal e histórico de Teresina, da capital. A história marca sua presença nesses termos espaciais. A função poética dessa apresentação está associada à necessidade do autor informar de onde surgiram tais poemas, a origem do criador dessa obra de arte que busca resgatar, rememorar sua infância, sua gênese. 


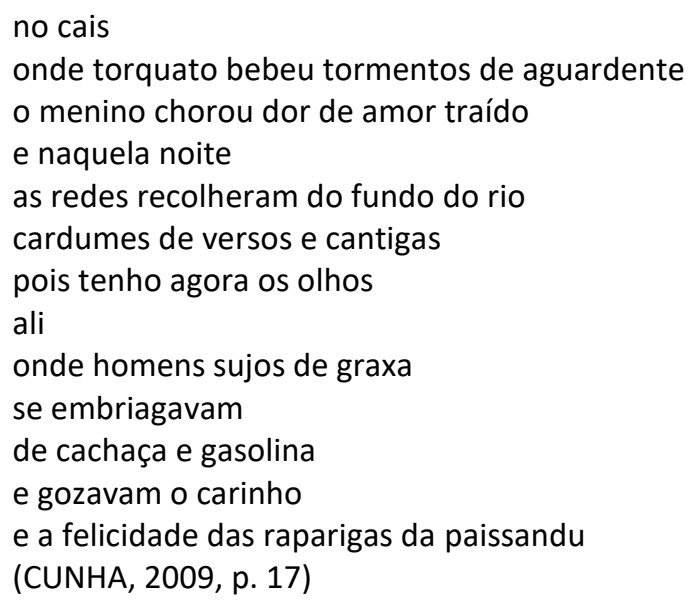

Neste trecho, o poeta busca descrever os espaços e os atos delineados por personagens marcantes na história. A citação do poeta tropicalista Torquato Neto trazendo, à luz do cais, sua atividade poética. O poeta chora amor traído, a consequência do choro faz surgir sua poesia, seus versos e cantigas. É também pela citação do nome de Torquato que o eu-lírico revela sua participação no envolvimento com a história, pois, ao passo em que cita o nome do poeta, também faz surgir em sua poesia, a categoria de tempo, um momento em que o tropicalista ganhava vida. A existência do poeta delimita o ano em que se passa o fato ocorrido, não há como dissociar o tempo histórico de sua produção, pois esse terceiro indica o desenvolvimento desse espaço. Já é possível descrever a transformação histórica que a Chapada do Corisco sofreu. Nela já se faz presente a Paissandu, zona boêmia de Teresina, atualmente transformada em área de comércio. Podemos perceber a liberdade que o poeta constrói em sua obra, sempre em letras minúsculas, com nomes próprios rebaixados a comuns. Esse confronto com a estilística não deixa de atribuir à obra do autor a beleza que emociona e incomoda o 
leitor. As verossimilhanças entre os registros históricos e o registro do poeta embriagado pelas lembranças de vida.

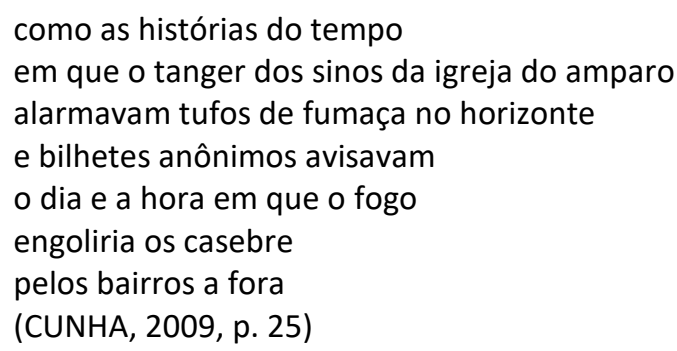

O incêndio sobre os casebres no centro de Teresina anunciava o avanço da capital, da transformação do espaço, do tempo. Tempo de "progresso", tempo de evolução, de beleza e arquitetura. Ali onde o poeta se recolhe tristemente em suas lembranças para falar de um fato consumido pelo fogo. Onde famílias com suas mazelas entregues ao desamparo, com seus teréns diluídos pelas chamas e fumaças, a Igreja Nossa Senhora do Amparo fazia tanger os sinos informando o novo incêndio da capital. É essa historicidade presente na obra que faz Moisés (2007) refletir sobre a função social da poesia no século XXI. Essa releitura da construção do centro da capital, da antiga Chapada do Corisco. O que vem a buscar o poeta por meio de sua escrita denunciativa e política na qual traz para sua obra acontecimentos ressignificados da história? A resposta seria a busca de informar, de dizer diferente por meio de outra ideologia.

miseráveis mal-agradecidos

(não entendiam a função profilática do fogo

ateado pelas digníssimas autoridades

a bem de espantar o fedor de sua miséria

e eliminar das vistas a imagem das choupanas de palha

incompatíveis com a elegância dos sobrados da nova capital inventada pelo conselheiro

(CUNHA, 2009, p. 26) 
O poeta faz surgir em seu texto vozes de outros sujeitos, de interlocutores, de ideologias que se contrapõem a voz do eu-lírico. O tom irônico que o autor utiliza para falar das autoridades faz escárnio das atividades surgidas nas relações políticas da época. A expressão lexical "digníssimas autoridades" faz com que o eu-lírico assuma um distanciamento ideológico e discursivo do ato. Há uma luta de classes na história que ganhou forma estilística na voz do poeta. Esse poeta que Platão expulsa de sua República, que faz mergulhar questionamentos e desordens no meio público é ratificado na escrita de José Cunha, com um corpo enunciador que faz o sujeito leitor mergulhar num deleite histórico e literário. Moisés disserta Platão acerca do poeta: "mais do eu peso morto, a poesia é uma ameaça à ordem e à estabilidade da República. O poeta, em suma, é expulso não por ser inútil ou incapaz, mas por ser perigoso" (MOISÉS, 2007, p. 35).

O poeta atribui voz a outro sujeito da história, atribui voz aos flagelos da natureza entregues ao bom homem nordestino:

\author{
o cheiro sem passado \\ nem futuro \\ dos retirantes \\ nos paus-de-arara \\ tangidos pela seca \\ amontoados \\ sob as arvores \\ da praça saraiva \\ os imigrantes do ceará \\ que fediam a fome \\ sezão \\ catarro \\ empilhados como latas vazias \\ enferrujados de poeira \\ entrevados de tanto chão \\ com pretume nos pés \\ (CUNHA, 2009, p. 44)
}


Esse personagem histórico que ganhou corpo em "Os Sertões" (1902), de Euclides da Cunha, assume a forma de um retirante, entregue à sorte de sua caminhada, de seu percurso. A forma como o poeta descreve esses retirantes da seca com tom pessimista, preocupado, engajado, traz para o texto outro discurso, o do descaso. Os sujeitos são levados do Ceará ao Piauí no velho transporte moldado por um caminhão, o pau de arara. Eles já não cabem nos bancos das praças, nem no solo. Amontoam-se em árvores, são sujeitos esquecidos pelo governo. O descaso os entrega à fome e às mazelas. Suas peles são desgastadas como latas enferrujadas. A metáfora "entrevados de tanto chão" dá voz aos longos caminhos a que os sujeitos estiveram submetidos. Os pés carregam as marcas do tempo e do espaço em que gastaram e percorreram. Essa voz denunciativa alerta ao leitor para as mazelas causadas pelo descaso do governo. A poesia assume a função de denunciar, de alertar ao leitor sobre o passado, sobre sua história e o poeta, por sua vez, busca recriar esse tempo/espaço de forma a sensibilizar o leitor. Segundo Silva:

As obras literárias registram os momentos de desespero, a falta de cuidado dos governos no trato dos flagelos, a corrupção das autoridades e pessoas destinadas a prestar assistência aos desamparados, a resistência de muitos em não deixarem suas terras e a solidariedade dos mais afortunados. $(2013$, p. 22)

A poesia de Paulo José Cunha possui a beleza de sensibilizar o leitor e um conteúdo que o leva a questionar e a refletir sobre a história. O poeta não está preso a valores de dominados e dominadores, mas busca trazer para o sujeito (leitor) uma reflexão sob um olhar diferente. A destreza com que o poeta carrega a obra faz com que sua escrita possua algo distinto de simples enumerações de acontecimentos. H. Dobal contribui para a poesia de Cunha. Em suas palavras, a obra Perfume de Resedá faz vivificar a antiga capital: 


\begin{abstract}
Uma das funções da poesia é desencantar lembranças, sujeita, no entanto, ao risco de tornar-se apenas uma prosaica enumeração. PJC cumpre esta função, evitando este risco. O seu mundo poético surge da poesia intrínseca das lembranças, realçada pelo poder que as palavras adquirem no contexto. As palavras vivificam as imagens e as pessoas: atrás da igreja das Dores o grotão por onde corriam as águas do inverno, a sua ladeira da Estrada Nova por onde se chegava à Pacatuba, onde hoje deve vagar o espírito irreverente do Vitinho, que ali freqüentou a aula de D. Maria Patu. (CUNHA, 2009, p. 9)
\end{abstract}

Essa breve apresentação da obra realizada por H. Dobal nos incentiva a mergulhar no poema de PJC e a experimentar as sensações do eu-lírico e a transformação da capital nessas lembranças descritas por um narrador que foi "ao mais profundo do oco do mundo" para entregá-las ao leitor.

\title{
Considerações finais
}

A obra possibilitou destacar alguns pontos importantes trabalhados para presenciar a relação entre história e ficção. Personagens marcantes da história como Torquato Neto, o conselheiro que promoveu o fogo nos casebres do centro da cidade, os espaços marcantes e presentes na capital, a transformação da Chapada do Corisco em Teresina e suas transformações categóricas nos revelam que esses traços propostos pelo narrador intrínseco, um eu-lírico que investe em revelar para seu leitor os castigos da seca, as cantigas e os causos de sua terra, de sua gente fazem com que sua obra artística se enquadre, em parte, para os romances (poemas) históricos regionais.

A função de Perfume de Resedá está em vivificar e testemunhar os acontecimentos região, fatos ganham novo olhar pelo olhar de um eu-lírico que cresce ao desenvolver a obra. É um saudosismo poético que faz uso do lúdico como valor agregado a suas memórias. Não se tem na obra fotografias históricas, relatos positivistas acerca de 
um espaço e tempo, mas a verossimilhança que eu-lírico retrata em sua obra. A literatura não surge para preservar a história. Ela vem para dar voz a histórias.

\section{Referências}

CUNHA, Paulo Jose. Perfume de Resedá. Teresina, Oficina da Palavra, 2009.

CHAVES, Flávio Loureiro. História e literatura. Porto Alegre: Ed. da UFRGS, 1991.

FREITAS, Maria Teresa de. Literatura e História: o romance revolucionário de André Malraus. São Paulo: Atual, 1986.

MOISÉS, Carlos Felipe. Poesia e Utopia: sobre a função social da poesia e do poeta. São Paulo: Escritureas Editora, 2007.

NIETZSCHE, Friedrich Wilhelm. C333 - A Gaia Ciência. Trad. Antônio Carlos Braga. São Paulo: Escala, 2013.

FERREIRA, Luiz Antônio. Leitura e persuasão: princípios de análise retórica. São Paulo: Contexto, 2010.

SILVA, Raimundo Celestina Mendes da. Para uma historiografia literária do Piauí: a narrativa da seca. Rio de Janeiro: Editora Caetés, 2013.

Recebido em 08 de dezembro de 2019.

Aceito em 05 de junho de 2020.

\footnotetext{
${ }^{1}$ Utiliza-se História com H maiúsculo para se referir a ciência, ao fato em si, a matéria mais positivista do fato, a documentação, a comprovação científica. Quanto a história com h minúsculo, refere-se a histórias contadas, narrações, personagens, tempo, espaço.
} 